\title{
Beitrag zur Kenntniss der Coleopteren-Gattung Calobius Woll.
}

Von Edm. Reitter in Mödling bei Wien.

In der Wiener Entom. Monatsschr. VIII, 1884, pag. 473 bis 478 hat bereits Graf Ferrari unter dem Anonymus eines süddeutschen Entomologen über die Gattung Calobius und die bis zu dieser Zeit bekannten Arten dieser Gattung beachtenswerthe Bemerkungen gemacht, welche zum grössten Theile noch heute zutreffen. Ferrari kam zu dem Resultate: 1. dass die Gattung Calobius wohl begründet sei; 2. dass Cal. notabilis Ros. nicht mit quadricollis Muls. synonym ist, welchen grossen Fehler auch heute wieder die letzte Katalogs-Ausgabe vom Neuen reproducirt. Ferrari beging in seinem Artikel leider den grossen Fehler, dass er, sowie es auch noch in der letzten Katalogs-Ausgabe geschieht, den Ochthebius subinteger Muls., der mit den Calobien nichts gemein hat, zu den Calobius-Arten rechnet, wodurch die Präcision der Gattung eine künstliche wurde. Diesen letzten Umstand scheint derselbe, als ihm der Ochthebius Lejolisii Muls. bekannt wurde, der eine ganzrandige Oberlippe besitzt, eingesehen zu haben, weil er in einer Nachschrift wegen der beiden letzten Ochthebien sein erstes Resumé, dass Calobius eine selbständige Gattung sei, widerruft und sie zu einer Section der Gattung Ochthebius stempelt, was sie gewiss nicht ist.

Herr Louis Bedel, der gewiss nicht in dem Verdachte steht, unnöthige Gattungen zu creiren, hat in seiner Faune des Coleoptères du Bassin de la Seine I (Paris 1881, pag. 291) eine Theilung der alten Gattung Ochthebius in 2 vorgenommen, indem er für Ocht. exsculptus Germ. und Verwandte, wegen des kleinen Endgliedes der Maxillartaster und der fast vollständigen Epipleuren, den Stephens'schen Namen Henicorus zur Gattung erhob.

Die Gattung Calobius entfernt sich jedoch schon habituell weit mehr von Ochthebius als Henicorus und unterscheidet sich von Ochthebius durch sehr grosse, lange, zweilappige Oberlippe, grossen, langen, vorn viereckigen Kopf, der der Breite des Halsschildes nicht nachsteht, durch sehr lange und dünne Beine, deren Schenkel dünn und deren Schienen statt mit Dörnchen mit feinen Härchen bewimpert sind; letzteren fehlen die Endsporen. Die Männchen haben die Aussenkante der Schienen

\footnotetext{
„Wiener Entomologische Zeitung" V. Heft 5. (15. Juni 1886.)
} 
mit langen Schwimmhaaren besetzt, welche aber leicht übersehen werden, weil sie sich ausserhalb des Wassers an die Schienen dicht anlegen. Während bei den Ochthebien sich der Hautsaum hauptsächlich an den Seiten des Halsschildes befindet, haben die Calobius-Arten ihn nur als schmalen Streifen am Vorder- und Hinterrand aufzuweisen. Die Calobius-Arten sind Meeresstrandthiere und bilden die natïrlichen Uebergangsformen von Ochthebius zu Hydraena.

Ferrari wurde zur Untersuchung der Calobius-Arten durch die Auffindung einer vermeintlich neuen Art aus Dalmatien veranlasst, fand aber, dass die dalmatinische Art identisch sei mit der von Mulsant als $O$. quadricollis beschriebenen aus Corsica.

Wie ich jedoch constatiren konnte, war diese Zusammenziehung keine gerechtfertigte.Von den dalmatinischen Exemplaren, welche Ferrari vorgelegen sind, befinden sich noch 2 im Hofmuseum in Wien und diese Stücke sind ganz übereinstimmend mit einer grösseren Anzahl einer Calobius-Art, welche Herr Steinbühler im Vorjahre am Meeresstrande bei Pola sammelte. Von der corsischen Art, die ihr sehr nahe steht, unterscheidet sie sich durch die spiegelblanke Oberseite, während namentlich Kopf- und Halsschild bei quadricollis hautartig reticulirt ist. Ich habe demnach die dalmatinische Art, welche übrigens auch auf der Ostküste Italiens vorkommt, unter besonderem Namen in die Wissenschaft eingeführt.

Uebersicht der bekannten Calobius-Arten.

1" Kopf kaum ganz so breit als der Halsschild. Vorderwinkel des Halsschildes eckig vortretend. Halsschild viel schmäler als die Flügeldecken, so lang als breit, mit tiefer Mittellinie und 6 tiefen Discoidaleindrücken. Flügeldecken mit dichten, tiefen, gekerbten Punktstreifen, Seitenrand in der Mitte aufgebogen. Andalusien . . . notabilis Rosenh.

1' Kopf sammt den Augen fast breiter als der Halsschild. Vorderwinkel des letzteren abgerundet. Halsschild wenig schmäler als die Flügeldecken, breiter als lang, Seitenrand der letzteren nicht aufgebogen.

2" Oberseite hautartig reticulirt.

3" Halsschild ohne Mittellinie, mit 4 tiefen, ovalen Eindrücken. Madera . . . . . . . quadrifoveolatus Woll. 
3. Halsschild wenigstens mit angedeuteter Mittellinie.

4" Halsschild jederseits ohne Eindrücke, wenig breiter als lang. Madera . . . . . . . . . . Heeri Woll.

4' Halsschild jederseits mit 2 mehr oder weniger deutlichen Grübchen, viel breiter als lang.

5" Flügeldecken wie die übrige Oberseite kahl. Südfrankreich, Corsica. (A. submersus Chevrl.) . . . . quadricollis Muls.

$5^{\prime}$ Flügeldecken sehr fein und spärlich reihenweise behaart. Cypern, Syrien . . . . . . . brevicollis Baudi.

2' Oberseite, namentlich der Halsschild glatt und glänzend, nicht hautartig reticulirt. Istrien, Dalmatien, Westitalien.

Steinbühleri n. sp.

\section{Calobius Steinbühleri n. sp.}

Oblongus, nigro-aeneus, nitidissimus, haud alutaceus, antennis fusco-testaceis, capite magno, cum oculis thorace fere latiore, antice parallelo, labro bilobo, vertice biimpresso; thorace transverso, basin versus magis angustato, angulis omnibus rotundatis, supra transversim leviter depresso, laevissimo, vix punctato, utrinque prope angulos anticos impresso, ante scutellum subfoveolato, elytris minutissime ruguloso-punctatis, palpis, tibiis, tarsisque piceobrunneis. Long. $1 \cdot 5-1 \cdot 8 \mathrm{mim}$.

Am Meeresstrande bei Pola von Herrn Steinbühler gesammelt, von Heller in Dalmatien, von de Marchi in Westitalien aufgefunden.

\section{Notiz über Choragus pygmaeus Robert.}

Von Dr. L. von Heyden in Bockenheim.

In Guérin Magazin de Zoologie, II, 1832, Classe IX, planche 16 ist von $\mathrm{R}$ obert ein bei Chênée près Liège au bord de l'Ourte gefundener Anthribide unter dem Namen pygmaeus beschrieben und abgebildet. Das Thier ist ganz sicher der Choragus Sheppardi Kirby 1818 - bostrichoides Müller 1821. Da die Art von Robert (und erst später 1874 von Motschulsky) beschrieben wurde, so ist $\mathrm{R}$ obert der Autor des Namens pygmaeus. Der Kirby'sche Name ist der älteste. $\mathrm{R}$ o b e r $t$ gibt $2 \mathrm{~mm}$ als Grösse an, darnach kann pygmaeus wohl nicht auf kleine Stücke des Sheppardi gedeutet werden, sondern ist einfach Synonym dieser Art. 


\section{$2 \mathrm{BHL}$ Biodiversity Heritage Library}

Reitter, Edmund. 1886. "Beitrag zur Kenntniss der Coleopteren-Gattung

Calobius WOLL." Wiener entomologische Zeitung 5, 197-199.

https://doi.org/10.5962/bhl.part.20583.

View This Item Online: https://www.biodiversitylibrary.org/item/43771

DOI: https://doi.org/10.5962/bhl.part.20583

Permalink: https://www.biodiversitylibrary.org/partpdf/20583

\section{Holding Institution}

Smithsonian Libraries

\section{Sponsored by}

Smithsonian

\section{Copyright \& Reuse}

Copyright Status: NOT_IN_COPYRIGHT

This document was created from content at the Biodiversity Heritage Library, the world's largest open access digital library for biodiversity literature and archives. Visit BHL at https://www.biodiversitylibrary.org. 